\title{
Evaluation of Land Suitability for Stone Pine (Pinus pinea) plantation in Lebanon
}

\author{
S. Kattar*, K. Abou Rjeily, Z. Souidi, G. Aoun, R. Moukarzel, G. Kallas \\ ${ }^{1}$ Lebanese University, Faculty of Agriculture and Veterinary Sciences, Department of Environment, P.O. Box 60-329 Beirut, \\ Lebanon. \\ ${ }^{2}$ University of Mustapha Stambouli de Mascara, SNV Faculty, Departement of Biology, POB 305, PôleSidiSaïd, Mascara, \\ Algeria.
}

\begin{abstract}
Stone pine (Pinus pinea) is a typical Mediterranean tree well adapted to drought and high temperatures. It is a species of great interest and economical importance in Lebanon and has a strong beneficial impact on the local communities from the marketing of its edible nuts. This tree is threatened by human activities and fire that are leading to its degradation. Therefore, the aim of this study is to delineate and map the suitability of soils for the plantation and extension of the stone pine. For this purpose, the adopted research methods were composed of the following three steps: (1) identifying through available data and traditional methods the ability of the lands to be planted with stone pine (2) identifying the various factors influencing the growth and fruiting of the treeand (3) transforming and integrating all the data into geo-referenced thematic maps and introducing them into the Geographic Information System (GIS) suitable for delimiting Lebanese areas suitable for planting stone pines. The obtained results were presented in a form of 10 thematic maps (GIS layers) that represent the influence of each ecological factor on the land suitability for afforestation by stone pine. A final thematic map that illustrates the most suitable areas for Pinus pinea plantations was generated by superimposing the $10 \mathrm{GIS}$ layers.
\end{abstract}

Keywords-Pinus pinea, forest plantation, suitability of soil, GIS, Lebanon.

\section{INTRODUCTION}

Stone pine (Pinus pinea L.) is a Mediterranean tree. It is well suited to high temperatures and drought (Montero et al. 2004), characteristic of Mediterranean climates. The total area covered by the forest of stone pine is about 380,000 hectares $(75 \%$ in Spain, 9\% in Portugal, 9\% in Turkey, 5\% in Italy), and lower percentages in Greece, Lebanon and France (Moussouris\&Regato 1999, Rego 2007).

In Lebanon, the stone pine forests cover the northern and southern Mediterranean facades exposure of Mount Lebanon to an altitude of $1200 \mathrm{~m}$ and represents $18 \%$ of total forest cover and $36 \%$ of coniferous forests or nearly 14000 ha (Baltaxe 1996). It is considered as one of the essential tree species that form the botanical richness of the Mediterranean phyto-sociology stages of the country. The multi-usage of its light and soft wood (carpentry, framing and especially in marine construction), the landscape value of this species and the use of its seeds in a wide variety of sweets, give the stone pine a high economic value (Calama et al. 2007).

In Lebanon and according to the Ministry of Agriculture, the total annual production was estimated at 1200-1500 tons for the period 2003 to 2005, with a total annual value of 16.5 to 25.8 millions of dollars. Most of the production comes from the Mount Lebanon region, especially Rass al-Metn and from the region of Jezzine. The price of one kilogram of seeds in the Lebanese market reached \$ 37 per kg (Nehme\& Johnson 2010).However, forest stands of pine trees in the country are threatened by deforestation, overgrazing, and urban development and fires (MOE / UNDP, FNRCBD2009). References show that during the past 40 years a decrease of $58 \%$ in the forest cover of the inner region of the Bekaa and 5 to $10 \%$ in southern and northern Lebanon (Masri et al. 2002).Currently, the priority in Lebanon is to promote afforestation and reforestation activities. Many actions and programs have been undertaken by the Ministry of Agriculture to compensate for the lossesin the forest cover over, and extends the next 20 years, including the program "40 million trees" (MoA 2012). The country has never had such ambitious reforestation movements. The choice of species is made after consultation and in collaboration with municipalities and local stakeholders. It turns out that stone pine is considered one of the most attractive species. The International Institute of Genetic Resources (IPGRI 1998), classified pine pinion among the top three most valued forest species in Lebanon. This classification is based on three main parameters: (1) the economic value of the tree, (2) the ecological value and (3) the risks that threaten it.However, favourable places to grow this tree were not geographically delineated by IPGRI (1998) or by reforestation plans adopted by the 
Ministries in Lebanon. Reforestation of stone pine implies knowledge of the available free surfaces, the soil types and the favourable climate conditions for the development of this tree. A Scientifically unjustified reforestation means loss of seedlings, repeated and costly work.Identifying proper planting locations requires; an up-to-date land use map, the availability of a database on soil types and a detailed understanding of the behaviour of the tree in relation to the environmental conditions. Most of the maps that were needed for this work were be reproduced, updated and digitized.

The purpose of this study is to classify the lands according to their ability to reforestation. This ability will be illustrated geographically in the form of a coloured thematic map with 5 classes of hierarchy from the most to the least favourable. This thematic map will become a key tool for the development of a reforestation plan where priority areas will be designated as well as the number of neededseedlings. The calculation of the total cost of the operation at the national level will be even possible.

\section{MATERIALS AND METHODS}

\subsection{Study zone}

Lebanon is located on the eastern coast of the Mediterranean Sea, between $36^{\circ} 66$ 'and $38^{\circ} 60^{\prime}$ latitude (Figure 1). Its area is $10,452 \mathrm{~km} 2$ and spans over $210 \mathrm{~km}$ length from southwest to northeast, with a width not exceeding $85 \mathrm{~km}$. It is characterized by a mountainous topography formed by two chains running from north to south parallel to the coast separated by the internal plain of Bekaa. This topography has divided Lebanon into four geographical zones (Murtada 2003):

1- The coastal area that forms a narrow border between the sea and the Mount Lebanon chain. It expands to reach $30 \mathrm{~km}$ in the plain of Akkar.

2- Mount Lebanon, a mountain chain ranging from $600 \mathrm{~m}$ in the south to $3080 \mathrm{~m}$ north. It gradually overcomes the sea to the peaks, while it forms a steep slope to the opposite side to the plain of Al Bekaa. At Beirut, this chain is crossed from east to west by the collar of Dahr alBaydar which influences the climate and biodiversity of the Mount Lebanon eastern exposure. This area is divided into two main bioclimatic stages. The first is of average altitude ranging between 500 and $1200 \mathrm{~m}$, divided by a series of narrow valleys. The second, a high altitude chain, reaching up to $3080 \mathrm{~m}$ of altitude at Kornet ElSawda.

3-The Anti-Lebanon is the eastern chain of the country with a peak of $2616 \mathrm{~m}$ at Tallat Moussa. The upper zone is a high and dried plateau. It is lower than Mount Lebanon and decreases gradually from south to north.

4- The interior plain Al Bekaa separates the two mountain ranges. It is a high plateau of $800 \mathrm{~m}$ of altitude and 133 $\mathrm{km}$ in length. Lebanon is characterized by a temperate climate with hot dry summer and mild and wet winter influenced by the cold winds of the west and north and sub-desert from the east and south. Five climatic units are present (Abi Saleh \& Safi 1988): the Thermomediterranean, the Eumediterranean, the Supramediterranean, the Montane Mediterranean and the Oromediterranean.

According to the soil map of Lebanon (Darwish et al. 2005), a high variability of soil types was observed. Stone pine is abundant on sandy soil. The soil has greatly influenced the landscape determining its floristic composition. Stone pine is associated with other vegetation, mainly Erica spiculifora, Gallipoli rose, Calicotomespinosa, Lavandulastoechas and Juniperus oxycedrus.

\subsection{Methodology}

The methodology is based on three main steps: (1) identify and characterize through available data and traditional methods the ability of the soil for stone pine plantation, (2) identify the various factors that influence the growth and the fruiting of the tree, and (3) transform and integrate all the data into geo-referenced thematic maps and introduce them into the Geographic Information System (GIS) suitable for delimiting areas suitable for stone pine plantation pine (Figure 2).

\subsection{Land Classifications}

The classification of lands suitable for the stone pine reforestation takes into account the topographical, soil and climatic factors (FAO 1984). Different information is derived from several maps from the National Remote Sensing Centre. Several field investigations have allowed us to update and validate the map information and identify all of the factors influencing the growth and regeneration of stone pine.

30 field trips were carried out according to the budget available and taking into consideration the unstable political situation in some areas of the country. A data set was collected: geomorphologic parameters (slope, exposure, altitude), pedologic (drainage, soil depth, $\mathrm{CaCO} 3, \mathrm{pH}$, texture, organic matter) and climate (precipitation, sum of annual temperatures, extreme temperatures) that affect the growth and fruiting of the tree.

The purpose is to arrange all these spatial and geometric data into an integrated system where they can be organized, analyzed and transformed into a map. Each spatial unit, referring to the soil and geo-climatic data, will advise us on reforestation potential of stone pine in Lebanon.

\subsection{Gradation of the ecological parameters}

The choice of appropriate evaluationof parameters is essential to successfully develop an evaluation method for 
land suitability (Olivas 2007). For the stone pine, we focussed on the biological and ecological characteristics of the lands rather than parameters that can be used in a more general framework for assessing lands suitability(Deng et al. 2014).

\subsubsection{Determination of criteria influencing land suitability}

The parameters of evaluation selected in this study are based on a large literature review taking into account soil and climatic requirements of the species.Soil properties such as soil type, $\mathrm{pH}$, organic matter and soil depth significantly influence the growth and existence of stone pine. A soil with a $\mathrm{pH}$ between 4 and 9 is the most suitable for the growth of pine. Values lower than 4 and greater than 9 cause inhibition of the extension of roots. Stone pine grows poorly on heavy, compact, clay or marl soils and prefers sandy loam and sandy soils and supports also stony and dry soils (Alexandrian 1982). A maximum of $50 \%$ of total limestone and $15 \%$ of active limestone is tolerated by the pine trees (Boisseau 1993). The organic matter content is also important because it improves the growth of the tree by increasing soil fertility (Becker et al., 1994). Weather conditions are also important to the growth of the species. The optimum rainfall varies from $550-1500 \mathrm{~mm}$ (Alexandrian 1982). In addition, this tree is sensitive to temperature above its absolute minimum (Rapp \&Cabanette 1981), in which the effect varies with altitude and exposure (Alexandrian 1982,Adili2012).The species can endure low temperatures between $-2^{\circ} \mathrm{C}$ and 7 - $\mathrm{C}$ on average during the coldest month, and high temperatures between $27^{\circ} \mathrm{C}$ and $30^{\circ} \mathrm{C}$ on average of the hottest months (Zaki 1978). The species comes into winter dormancy when low temperatures become unfavourable for its growth. During harsh winters, it is the least resistant among all conifers (Vazhov et al. 1988). For this reason, Boisseau (1993) considered the correlation of temperature with altitude as an indicator of upper limits to the Mediterranean expansion of this species. According to Labadie (1983), stone pines prefer humid climate (> 70\%). In addition, topographic factors (i.e. slope and elevation) play an important role in the distribution of moisture and temperature (Deng et al. 2014). The tree manifests itself best on flat lands and with a slope of less than 8 degree (Alexandrian 1982).

\subsubsection{The weight (pi) of the ecological parameters}

Based on the literature reviews, it is confirmed that several environmental factors have different effects on the growth of stone pine. Therefore, the weight determination of parameters is an important step for the development of a model equation. There are many methods for determining the weight of parameters (Deng et al. 2014). To assign weights to the parameters used in this analysis, comparisons were made between these parameters. In result of these comparisons, each parameter was attributed a weight from 1 to 5 depending on its importance (Partoune\&Quoilin2002). It varies in ascending order from 1 (limiting factor) to 5 (least influencing) by providing significant value to the best environmental conditions. For example, calcium carbonate will have a low weight of around 2 (limiting factor), while the factor that ensures better conditions of the tree, like the rate of organic matter in soil (fertility) or exposition will have a higher weight equivalent to 4 . These weights were awarded following an extensive literature review and in collaboration with 5 forestry specialists taking into account local conditions of the study area.

\subsubsection{Gradation and standardization of the ecological parameters}

In the context of Geographic Information System (GIS), it was necessary to calculate land suitability based on the ecological factors specific to the development of Pinus pinea trees (J Malczewski 2006). An equation model was established to enable the GIS to filter the data. This equation 1 is used to classify a given location (i) using the coefficients and weights assigned to each environmental parameter retained.

$$
\text { Classe }=\frac{\sum_{1}^{\mathrm{n}} \mathrm{Cipi}}{\sum_{1}^{\mathrm{n}} \mathrm{pi}} \times \mathrm{Y} \quad \text { (equation } 1 \text { ) }
$$

Where, $\mathrm{Ci}$ is the coefficient value allocated to each rank of parameter gradations; $\mathrm{Pi}$ is the weight given to each parameter; and $\mathrm{Y}$ is the coefficient of the most important limiting factor for a given location.

The coefficient $(\mathrm{Ci})$ was estimated on the basis of bibliographic data and several field observations (Table 1). The coefficient $(\mathrm{Ci})$ varies from 0.1 (worst) to 1 (optimal). However, the values of some parameters cannot be segregated because of their weak variations (like in the case of $\mathrm{pH}$, which almost always oscillates around 7); they will be considered homogeneous over the entire study area and will not be taken into account. Also, all values of $\mathrm{Ci}$ are not represented for all parameters. A deliberate choice was made for every variation of the parameter considered in light of the ecological constraints observed in the field.Therefore empty boxes (N/A) appear in the weighting table (Table 1). Each parameter is spatially represented in the form of a thematic map to enable visualization and analysis. Secondly, and in order to maintain the values ranging from 0 to 1 , the sum of the values (Ci.pi) of each station will be divided by the sum of their weight (pi). The resulting number will always be less than 1 classifying the sitesfrom "most suitable" to the "non-suitable" for Pinus pineareforestation.In order to prevent a non-suitable sitefrom having a high rating, in cases when all other conditions are favourable, a factor (Y) was added at the end of the calculation to eliminate 
the non-suitable sites. The multiplicative factor $(\mathrm{Y})$ will differentiate between the classes of suitability emphasizing the importance of the limiting factor. The factor $(\mathrm{Y})$ represents the most restrictive parameters of the coefficient $(\mathrm{Ci})$ gradation in cases when it is not suitable to plant the pines even if the other parameters are suitable.

Based on land suitability characteristics for different crops, FAO (1976) proposed a land suitability evaluation by differentiating five classes: highly suitable, moderately suitable, marginally suitable, currently not suitable and permanently not suitable.In our study, five classes are differentiated by the land's ability for stone pine reforestation:

- Class 1: Highly Suitable $>0.8$

- Class 2: Suitable 0.6 to 0.8

- Class 3: Moderately Suitable or Average 0.4 to 0.6

- Class 4: Low suitable 0.2 to 0.4

- Class 5: Not suitable $<0.2$

\subsection{Generating the database in a ArcGIS platform}

To illustrate these parameters in the form of thematic maps, we used the computerized database of the National Remote Sensing Centre. The maps used are:

- The soil map of Lebanon (Gèze 1956),

- The Digital Model of the Land (M.N.T.) with contour lines every 50 meters,

- The rainfall map of Lebanon (Plassard 1972),

- The Climatic Atlas of Lebanon Tom. II (Blanchet 1976),

- $\quad$ The land cover map to scale $1 / 20000$ recently prepared with the IRS satellite images 5 meter spatial resolution (CNRS, MoA, MoE 2002).

These maps helped to constitute the various thematic layers (GIS Layers) according to the weighting table (Table 1). We worked under the ArcGIS - ESRI. The crossing of different layers, generated from the equation 1 , in GIS resulted in the final map of the ability of Lebanese land for stone pine reforestation.

\section{RESULTS}

3.1.Identification of constraints to reforestation of pinion pine

\subsubsection{Soil occupation}

The first step undertaken begins by identifying favourable areas for reforestation according to land availability. So, it was excluded the territories occupied by urbanization, agriculture and dense forests, as well as water surfaces and beaches according to Lebanese soil occupation map at the scale 1:20 000 (CNRS, MoA, MoE 2002). This card includes 4 levels of classification. The first level consists of 9 classes which then detailed in 86 subclasses. In order to transform this map into thematic map layer (Layer GIS), this map was simplified into 5 classes (Figure 3).
First class is bare and rocky soils that are considered in principle as priority areas for reforestation with the highest coefficient of 1 (best station), followed by fire and shrublands. Then come the free surfaces in sparse forests, since the vegetation of these forests does not exceed $60 \%$ of their total area. In contrast, the dense forests are not completely excluded in the reforestation of stone pine, due to the free surfaces that sometimes exceed $40 \%$. The given coefficient to the latter had a significant weight (Table 1). Similarly, for agricultural and urban land, afforestation by the stone pine is not excluded. It takes sometimes the form of hedges around houses and gardens as well as along highways.

\subsubsection{The climate}

Climatic factors are not limiting factors, but they usually play a negative role in the growth and fruiting of stone pine. These factors are numerous, such as: precipitation, extreme low temperatures of the coldest month, the rate of evapo-transpiration, wind etc.The data for these parameters are sometimes available, sometimes incomplete or require additional work to their finding and compilation. In this work, we have selected only the two thematic maps for extreme low temperatures of the coldest month (January) and the amount of annual rainfall in order to define the most favourable areas for stone pine reforestation.

\subsubsection{The Minimum temperatures}

The Mediterranean region characterized by a mild spring with a maritime influence (moisture), is most favourable to this species. Most continental regions where extreme low average temperature of the coldest month is less than 0 or $5^{\circ} \mathrm{C}$ are considered moderately favourable (Figure 4 ). In the inner regions of Beqaa valley where temperatures are below $0^{\circ} \mathrm{C}$, vegetative growth of the tree is low. In the mountains high altitudes where the average temperatures are negative, stone pine is damaged by the snow that causes breakage of branches. However, the afforestation by this species remains possible given the pine forests which are at 1300 and 1400 meters above the sea. The coefficient assigned to these regions in the weighting table is 0.6 . On the other hand, mountain regions where temperatures drop below $-5^{\circ} \mathrm{C}$ (extreme limiting factor) fall into the category of inappropriate places for reforestation by this tree.

\subsubsection{Annual precipitations}

With the exception of the semi-arid northeastern Lebanese zone where annual rainfall is less than $300 \mathrm{~mm}$ considered unfavourable, all Lebanese regions are favourable for growth and fruiting of stone pine where rainfall is often higher than $700 \mathrm{~mm}$. However, the most favourable places are those with rainfall greater than 900 mm (Figure 5).

\subsection{The topography}




\subsubsection{The altitude}

The altitudinal parameter reflects indirectly several clues at once: temperature, rainfall, evapotranspiration and soil moisture. The two Mediterranean stages thermo and Meso (between 0 and 1000 meters above sea level) are considered the most favourable to the stone pine (Figure 6). Beyond this elevation, snowfall causes breakage of branches and acts as a limiting factor in the production of the tree. Altitude between 1000 and 1300 meters corresponds to the coefficient 0.5 regions that exceed 1300 meters are unfavourable.

\subsubsection{The slope}

The influence of the slope is seen in two complementary negative aspects: first, as an index of erosion, which weakens the soil fertility; the second, as an obstacle to the mechanization of work since the stone pine can be planted as a fruit tree. However, it manifests in crusts and rocky escarpments. It is recommended for reforestation of degraded areas (Figure 7). The coefficient given to over $30 \%$ steep slopes is not so weak, it is of the order of 0.4 but a strong weight is assigned in the order of 4 .

\subsubsection{The exposition}

Stone pine is reforested for profits as a fruit tree. The availability of water is a requirement for good production. Evapotranspiration is always less accentuated on the northern exposure than the sunniest southern exposure that will be assigned a lower coefficient. In the weighting table (Table 1), only three classes are distinguished because of the proximity of values and low variation of this factor. The values range from 0.8 for the northern exposure and 0.6 for the South exposure. The stations of all exposition, considered as plateaux facilitating the access to light, soil moisture and work mechanization, are the most favourable (Figure 8).

\subsection{The pedology}

\subsubsection{The Soil depth}

The soil physical characteristics are more important to the stone pine that its chemical characteristics. The tree can adapt to different soil types, from the poorest to the most profound. But fertility affects productivity and vigour of the tree. All soils with a depth exceeding $10 \mathrm{~cm}$ are considered suitable for reforestation (Figure 9). However, the coefficient assigned to different depths is not the same. It is given the maximum value 1 for soils with a depth exceeding 1 meter and minimum 0.6 for those with depths ranging between 10 and $50 \mathrm{~cm}$ (Table 1).

\subsubsection{Organic Matter}

The majority of the Lebanese soils are poor in organic matter. The amounts found throughout the country do not exceed usually $2 \%$. The contribution of manure from poultry that is free in the mountain areas has been successful. The tree tolerates sandy soil and can also adapt to the rocky soils (Figure 10). The fertility index an important factor in the production of the tree, which is manifested by the percentage of organic matter in the soil is low. This is reflected in the weighting table with high weight of 4 , but the coefficients that is maintained at 0.5 . These coefficients are not far from the poor and rich soils. They range from 1 for fertile land and 0.5 for soils with less than $1 \%$ organic matter.

\subsubsection{Calcium carbonate $\mathrm{CaCO}_{3}$}

Although the stone pine adapts to different types of soil, the vigour of the tree and its fruit depends largely on the lime content in the soil. The forests that grow on soils formed based sandstone can regenerate spontaneously, unlike the planted forests on calcareous soils where human intervention is necessary. For this reason, the minimum weight given to this parameter is 2 . In the other hand, the best coefficient 1 is assigned to the soil completely devoid of $\mathrm{CaCO} 3$. However, soils with an amount that exceeds $30 \%$ are not considered tolerable by this species (Figure 11) and their ratio remains above 0.4. 3.3.4. Soil texture

For this tree, soil texture is a major limiting factor especially for seedlings germination (Figure 12). In general, the tree tolerates light and well drained soils with the presence of deep groundwater and stony soils. For extreme cases, in heavy, clay or overly compact marl soils, this species grows poorly due to poor structuring and aeration in the soil (Boisseau 1993, 1996). For these reasons, the weight given to this parameter is the one closest to the limiting factor 2 , and the coefficients of land having a compact texture (i.e. fine and very fine) have minimum values of respectively 0.2 and 0.4 .

\subsection{Map of stone pine reforestation opportunities in Lebanon}

We took into account the influence of each parameter according to the weighting table (Table 1) and generated 10 thematic maps (GIS layers). The intersection of all the information in the form of thematic layers allow us to reach a final map (Figure 13). Unlike previous maps, where the classification depended on the weight given to each station, the classification of potential areas for stone pine even more delicate since the spatial units no longer carry weight, but the result of repeated multiplication of the weight inherited by all factors.In order not to lead to a fragmentation of stations following this intersection, the stations having the same final weight after each intersection were merged together to form a homogeneous spatial unit (USH). Similarly, the area of stations less than 4 ha were fused with the largest terraced station. Based on this logic crossing cards and multiplying the respective weight for each station, we have reached the final card of the rank of land according 
to their potential for reforestation of pinion pine (Figure 13).

\section{DISCUSSION}

The final map is obtained using the geographic information system (GIS) on the ERDAS software. Figure 13 provides a clear delineation of very favourable land for reforestation of stone pine; they occupy an area of 25,365 hectares. This category also adds an area of 21,765 hectares representing favourable land with a total area of 47130 hectares. These two classes that are distinguished are considered priority for reforestation. They represent nearly $5 \%$ of the entire Lebanese territory. This percentage is considerable given that the total forest area in Lebanon according to NFA (2010) is nearly $13 \%$ (136 000 hectares). It is observed that the concentration of favourable land (to the state) reforestation by this tree are not only those based on geological basalt (the plateau of Akkar) or lower Cretaceous (Upper Metn and Jezzine) that means devoid of limestone carbonate but also those who are training on compact limestone (the Lebanese south case). However, it appears that the region of Jezzine-Nabatieh is currently the least provided by a leafy forest cover, although the Mediterranean climatic conditions are favourable for reforestation by this forest species. The agricultural vocation of the internal Bekaa and its dry climate pre-steppe appears as an obstacle to reforestation by stone pine. This constraint can be considered as the limiting factor for Mount Lebanon and eastern exposure to the eastern chain (Anti-Lebanon) which now is placed in the category of land with little or unfavourable reforestation by the stone pine. The moderately favourable land reforestation by this tree occupies 56,300 hectares, or approximately $6 \%$ of the entire Lebanese territory.It ultimately appears that the classification of these lands is a compromise between several factors and parameters. The results were validated from the land use map. However, an update can be seen from the data and maps and now renewed by the Remote Sensing National Center with better resolution. In addition, several aspects were not addressed in this study, including the logistics (roads), the forestry aspects (density and planting methods, thinning, production and operating age) and status land (state, municipalities, individuals ...). But many constraints did not allow us to have access to this information.However, this work has well demonstrated the relevance of GIS for making synthesis maps that can be very useful for field managers. Nevertheless, it is important to stress that constant updating is expected following the changes that can take place before the complete planting of all land identified suitable for reforestation with the species. Also, other parameters (roads, water etc.) can be integrated according to the assigned objectives.It would also be interesting to extend this methodology to other important species for reforestation in Lebanon. A synthesis map that helps to identify the suitability of soils for reforestation according to the species is a decisive factor for the development of forests in Lebanon.

\section{CONCLUSION}

The Lebanese government has set the goal of achieving forest coverage of $20 \%$, or 70000 hectares must be reforested in the coming years. So this work has focused primarily on mapping soil and climatic factors, component necessary, even essential, to achieve a plantation program.Our goal was primarily to result in operational maps for the land manager. The results were presented to officials and decision makers from the Ministry of Agriculture, who are very interested in the methodology and wish to invest in such an approach to facilitate the identification of areas to be reforested.It is clear that this cartographic base is only a starting point for such an ambitious goal. The field manager will implement a strategy of planting where the proposed maps can find all their interest as they allow delineating the Lebanese territories according to their potential. But we must not lose the supply of seeds that will be provided by the Ministry of Agriculture for each region from the elite trees and orchards in pre-identified seed.However, in the future, all this information must be supplemented by field experiments and a network of permanent plots (not currently available in Lebanon). This will enable closer monitoring of stone pine (or other species) to establish indicators of fertility and yield tables for each zone and validate the results.

\section{ACKNOWLEDGMENT}

This article is a tribute to the late Professor Talih El Masri a member of the CNRS remote sensing team, he was the initiator of this work. He supervised, facilitated, and never hesitated to share his knowledge. We also wish to express our sincere thanks to the Lebanese Remote Sensing Centre that provided us with databases, research means and the technical nature of Geographic Information System (GIS) for the realization of this work.

\section{REFERENCES}

[1] Abi Saleh B. et Safi S., 1988. Carte de la végétation du Liban. EcologiaMediterranea XIV (1/2) pp. 123141.

[2] Adili B., 2012. Croissance, fructification et régénération naturelle des peuplements artificiels de Pin pignon (Pinus pinea L.) au nord de la Tunisie. Sciences agricoles. Universit'e Blaise Pascal Clermont-Ferrand II. 
[3] Alexandrian D., 1982. Le pin pignon. Forêt méditerranéenne, t.IV, $n^{\circ} 2$.

[4] Asmar F. R., 2003. National Report on the Forestry Sector in Lebanon. April 2003. Ministry of Agriculture, Republic of Lebanon.

[5] Baltaxe R., 1966. Forest map of Lebanon 1:200,000 scale. Base on the 1/50,000 scale forest type map of Lebanon. Forestry Education, Training and Research Project, Green plan, Lebanon.United Nations Development Program-Special Fund/FAO.

[6] Blanchet G., 1976.Le temps au Liban, approche d'une climatologie synoptique. Thèse de 3e cycle, Lyon. T. II : (Atlas).

[7] Becker R.D., Cosgrove J., Doll C., Grau K., Kelling N., Martin M., Rice M., Schmitt D., Wedberg J., 1994. Alfalfa management guide. Am Soc Agron, Madison, WI, USA.

[8] Boisseau B., 1993. Biologie et forêt: Ecologie du pin pignon. Informations techniques du CEMAGREF, Décembre, $\mathrm{N}^{\circ} 92$ note 5. p.1-8.

[9] Calama R., Madrigal G., Candela J.A. and Montero G., 2007. Effects of fertilization on the production of an edible forest fruit: stone pine (Pinus pinea L.) nuts in south-west Andalusia. InvestigacionAgrariaSistemas Y RecursosForestales 16(3): 241-252.

[10] Choueiter D. and Ucenic C., 2007.Pinus Pinea L. Forest, a Very Important but Threatened Ecosystem in the Lebanon. In: Proceedings of the 2nd IASME/WSEAS International Conference on Energy and Environment EE'07, USA. 264-268.

[11] CNRS, MoA, MoE, 2002. La carte d'occupation des sols au Liban échelle 1/20000.

[12]DarwishT.,Khawlie M.,Masri T., Faour G., Awad M.and Jomaa I., 2000. Producing the soil map of Lebanon and the SOil-TERrain database (SOTER at $1 / 50000$ scale). Abstracts of the $14^{\text {th }}$ Science Meeting.NCSR-LAAS.p.18. Held in AUB. Beirut, Lebanon. 23- 25 November.

[13] Darwish T., Jooma, I., Awad M. and AbouDaher M., 2005.Inventory and Management of Lebanese soils integrating the Soil Geographical Database of Euro-Mediterranean Countries.Lebanese Science Journal. 6 (2) 57-70.

[14]FAO, 1984. Land evaluation for forestry.FAO Forestry Paper 48. Rome, Italy.

[15]FAO, 1991. La carte de l'occupation du sol au Liban (échelle 1/50000).

[16]FAO on-line publications, http://www.fao.org/docrep/x5593e/x5593e00.htm

[17]FAO, 1976. A framework for land evaluation.Food and Agricultural Organization of the United Nations, Rome.
[18]Fei Deng, Xiaobing Li, Hong Wang, Meng Zhang, Ruihua $\mathrm{Li}$ and $\mathrm{Xu} \mathrm{Li,} \mathrm{2014.} \mathrm{GIS-based} \mathrm{assessment}$ of land suitability for alfalfa cultivation: a case study in the dry continental steppes of northern China. Spanish Journal of Agricultural Research 12(2): 364-375.

[19] Gèze B., 1956. Carte de reconnaissance des sols du Liban. Echelle 1/200000 avec notice explicative. Ministère de l'agriculture, Beyrouth, Liban.

[20]IPGRI, 2001. Development of research activities on the conservation and use of forest genetic resources in Lebanon.Workshop report, Beirut 14-15 May 1998.International Plant Genetic Resources.Rome, Italy pp. 24.

[21]Labadie J., 1983 - Étude des exigences écologiques du Pin pignon en région méditerranéenne française. Mémoire de troisième année ENITEFCEMAGREF

[22]Malczewski J., 2006. GIS-based multicriteria decision analysis: a survey of the literature. Int $\mathbf{J}$ GeogrInfSci 20:703-726.

[23] Masri T., Khawlie M., Faour G., 2002. Land cover change over the last 40 years in Lebanon. Lebanese Science Journal V.3, No 2. pp. 17-28.

[24] MoA, PNUE, 1996. Etude de la diversité biologique du Liban. T.3, 147 p.

[25] MoA, 2012. National Reforestation Program

[26] http://www.agriculture.gov.lb/Arabic/NewsEvents/P ages/MOA 40Million Trees.aspx

[27] MOE/UNDP, FNRCBD, 2009. Ministry of Environment-Lebanon.Fourth National Report of Lebanon to the Convention on Biological Diversity.

[28] Montero G., Martinez, F., Alia R., Candela J.A., Ruiz-Peinado R., Canellas I., Mutke S. and Calama R., 2004. Generalidades de Pinus pinea L.In El pinopinonero (Pinus pinea L.) enAndalucia.Ecologia, distribucion y selvicultura.Edited by G. Montero J. A. Candela, and A. Rodriguez.Consejeria de Medio Ambiente, Juntade Andalucia, Sevilla.

[29] Mourtada A., 2003. Traitement des données climatiques existantes : contribution à l'élaboration des zones climatiques au Liban, Séminaire thermique du bâtiment au Liban : Améliorer la conception de l'enveloppe. Beyrouth.

[30] Moussouris Y. and Regato P., 1999. An overview of non timber forest products in the Mediterranean region.

[31] Nijkamp P., 1993. Design and use of geographic information systems and spatial models, in Fichier M.M., Nijkamp P.(eds), geographic information systems , spatial modeling, and policy evaluation, 1993.Rego F.C. 2007. Resultados do IFN 2005 | 06. In Cerimónia de Apresentação do 
InventárioFlorestal Nacional (2005/2006). Edited by DGRF, Auditório do Arquivo Nacional da Torre do Tombo, Lisboa.

[32] Olivas GUE, Valdez LJR, Aldrete A, Gonzalez GMdJ, Vera CG., 2007. Suitable areas for establishing maguey cenizo plantations: definition through multicriteria analysis and GIS. Rev Fitotec Mex 30: 411-419.

[33]Rapp M. et Cabanette A., 1981. Biomasse, minéralisasse et productivité d'un écosystème à pin pignon (Pinus pinea L.) du littoral méditerranéen. Partie III Croissance. Acta Oecologia/ Oecologiaplantarum, p.121-136.
[34] Plassard, J., 1972. Service météorologique du Liban, Observatoire de Ksara : Carte pluviométrique du Liban au 1/200 000 avec notice. Beyrouth, Ministère des Travaux publics et des transports, Direction générale l'aviation civile, 39 p.

[35]Vazhov VI., Yaroslavtsev GD., Kuznetsov SI., 1988. Reaction of exotic conifers to the harsh winter of 1984/85 in the Ukrain.Bulletin - GlavingoBotanickeskogo-Sada. $\mathrm{N}^{\circ} 149$, p.12-17.

[36]Zaki A. Guide pratique de reboiseur au Maroc 1978. Ministère de l'agriculture et de la reforme agraire. pp.5.

[37]Zinette M., 1998. Mémoire de fin d'étude, Université Libanaise. Facultéd'Agronomie. pp 77.

\section{Figures and tables}

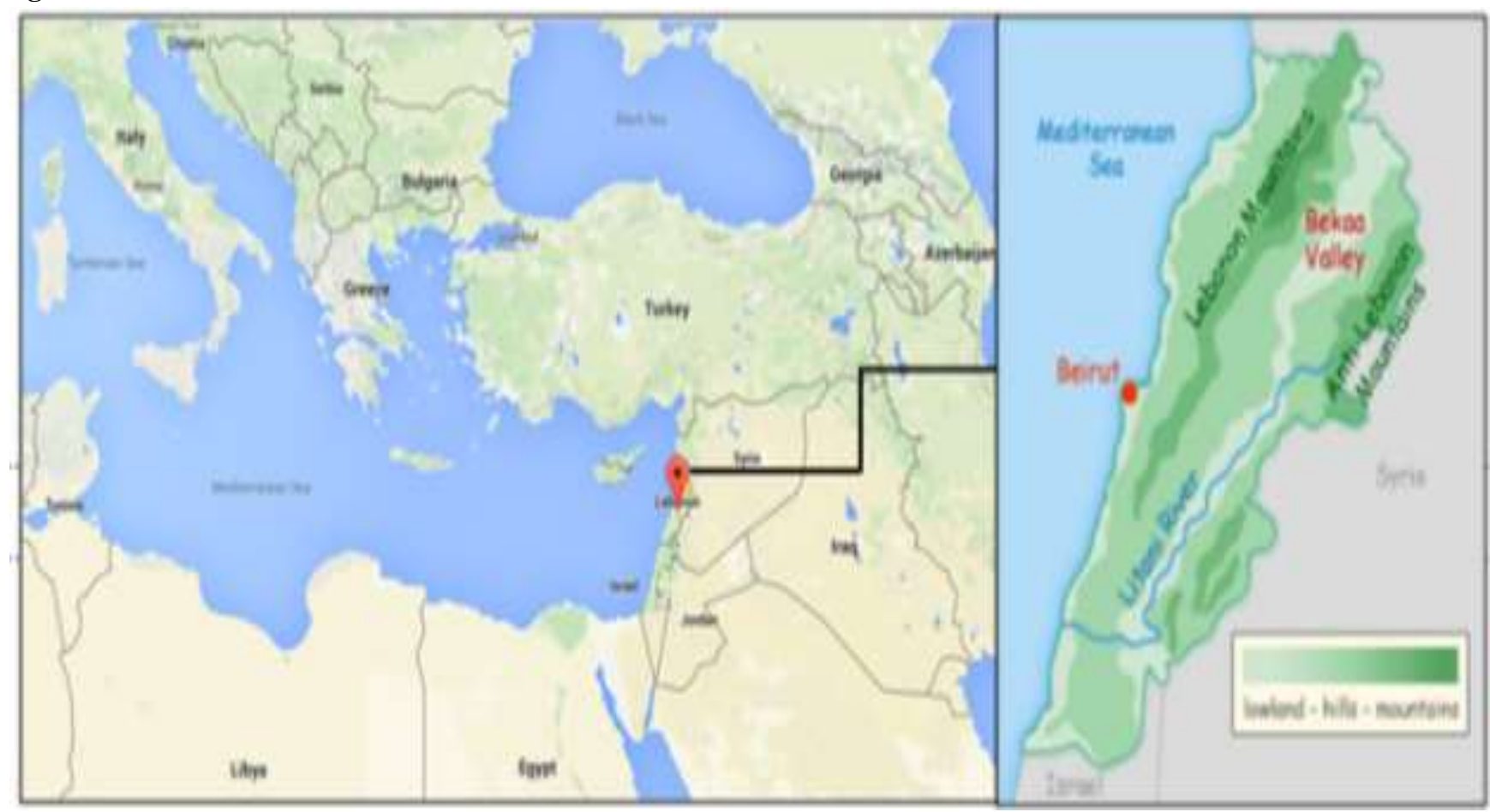

Fig.1: Geographical location of Lebanon according to Mediterranean basin (Google map, www.globaleye.org.uk), and the various topographical zones. 
Identification of parameters that affect the development and fructification of Pinus pinea

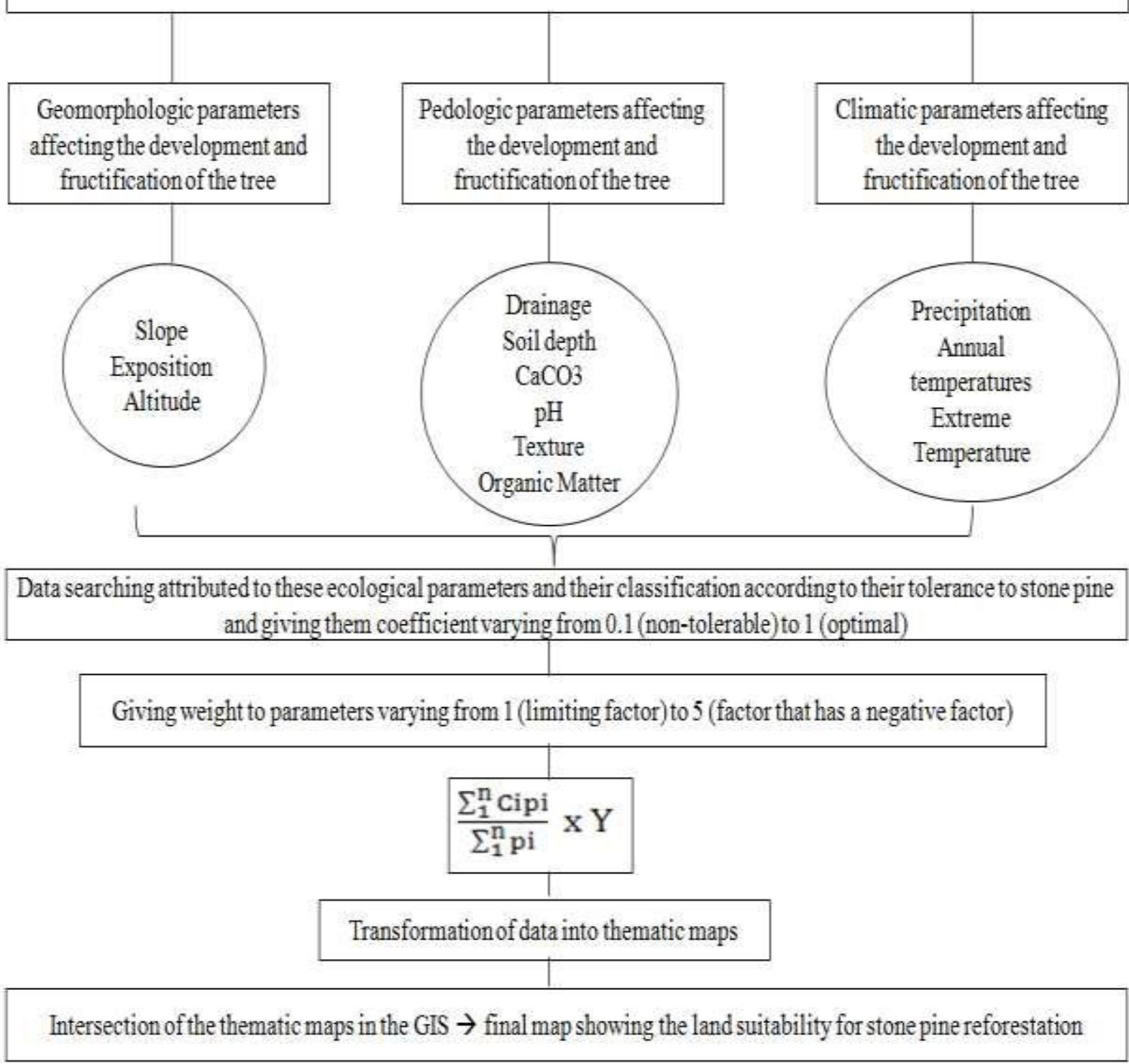

Fig.2: Flowchart of the methodology adopted in this study. 


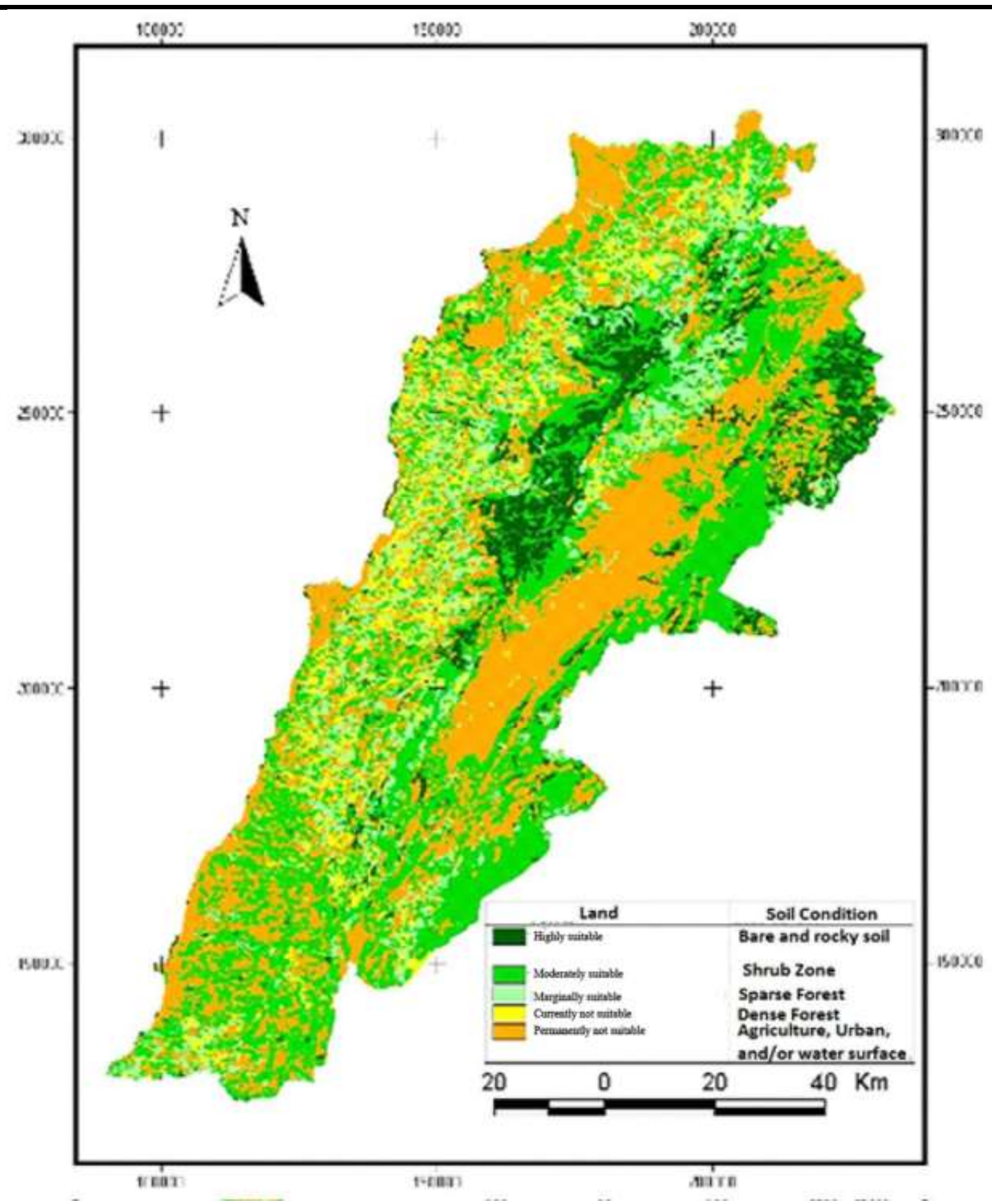

Fig.3: Ability of the Lebanese territory for stone pin reforestation according to land's occupation. 


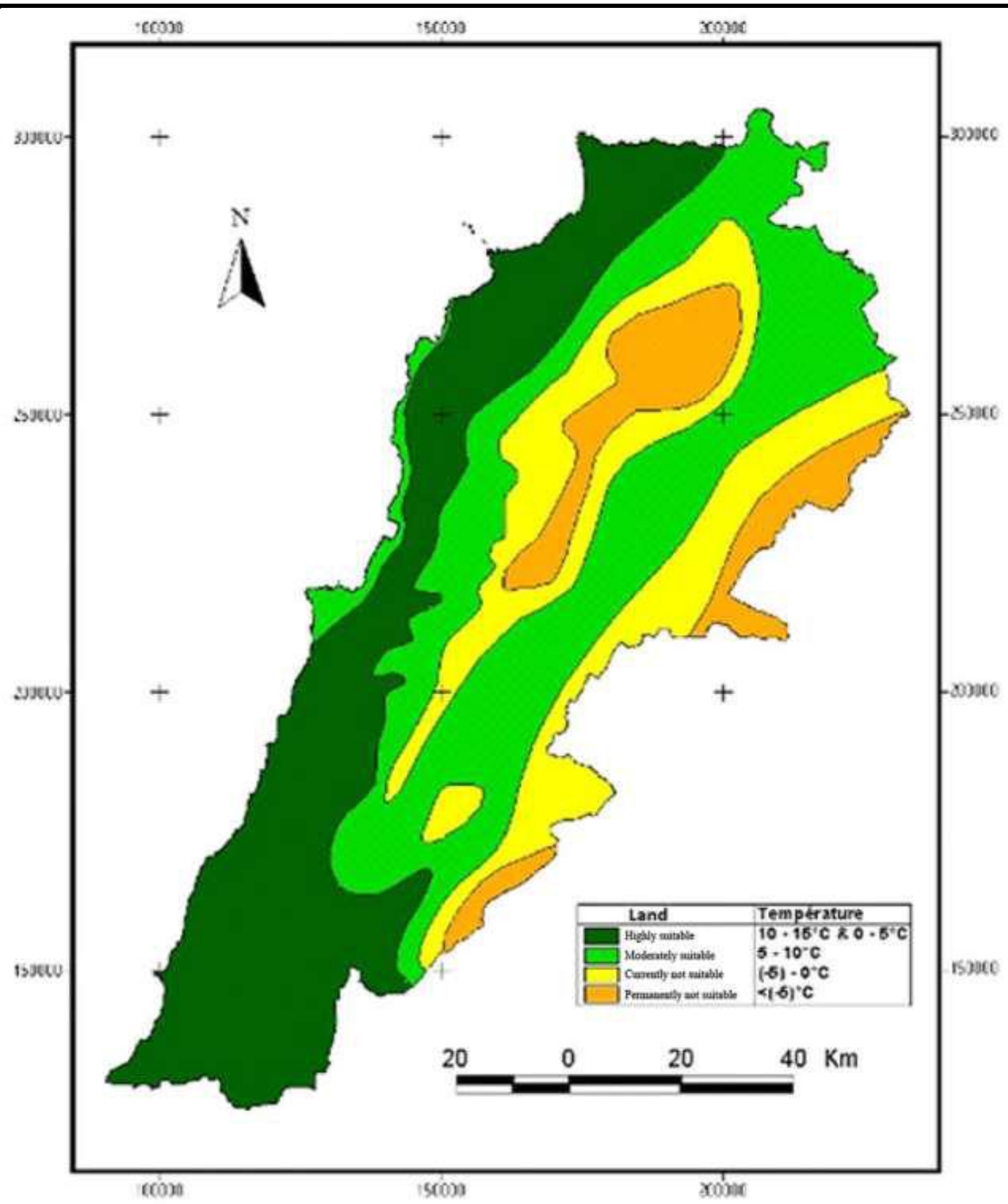

Fig.4: Ability of the Lebanese territory for stone pin reforestation according to the extreme minimum temperatures. 


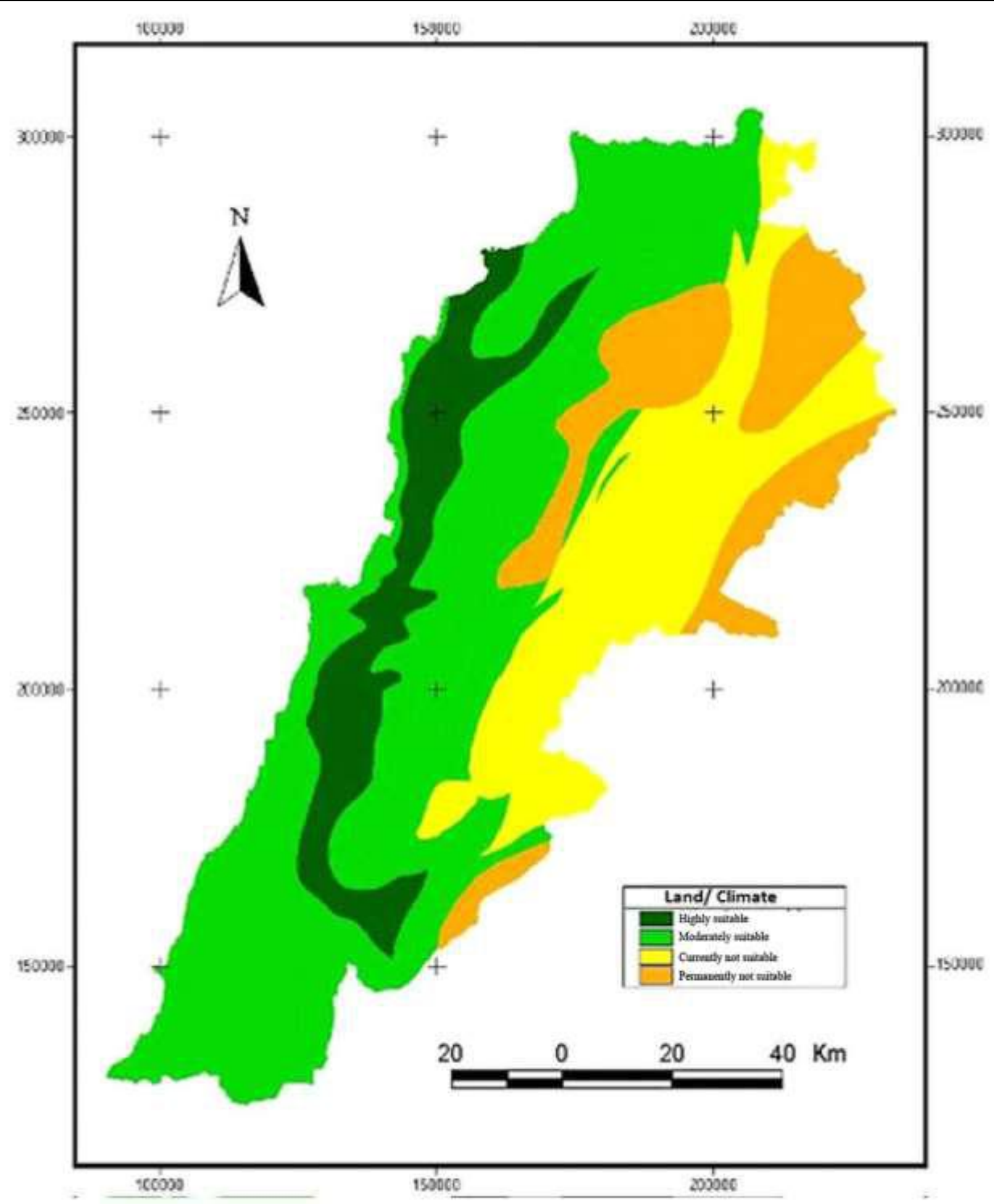

Fig.5: Ability of the Lebanese territory for stone pin reforestation according to climate. 


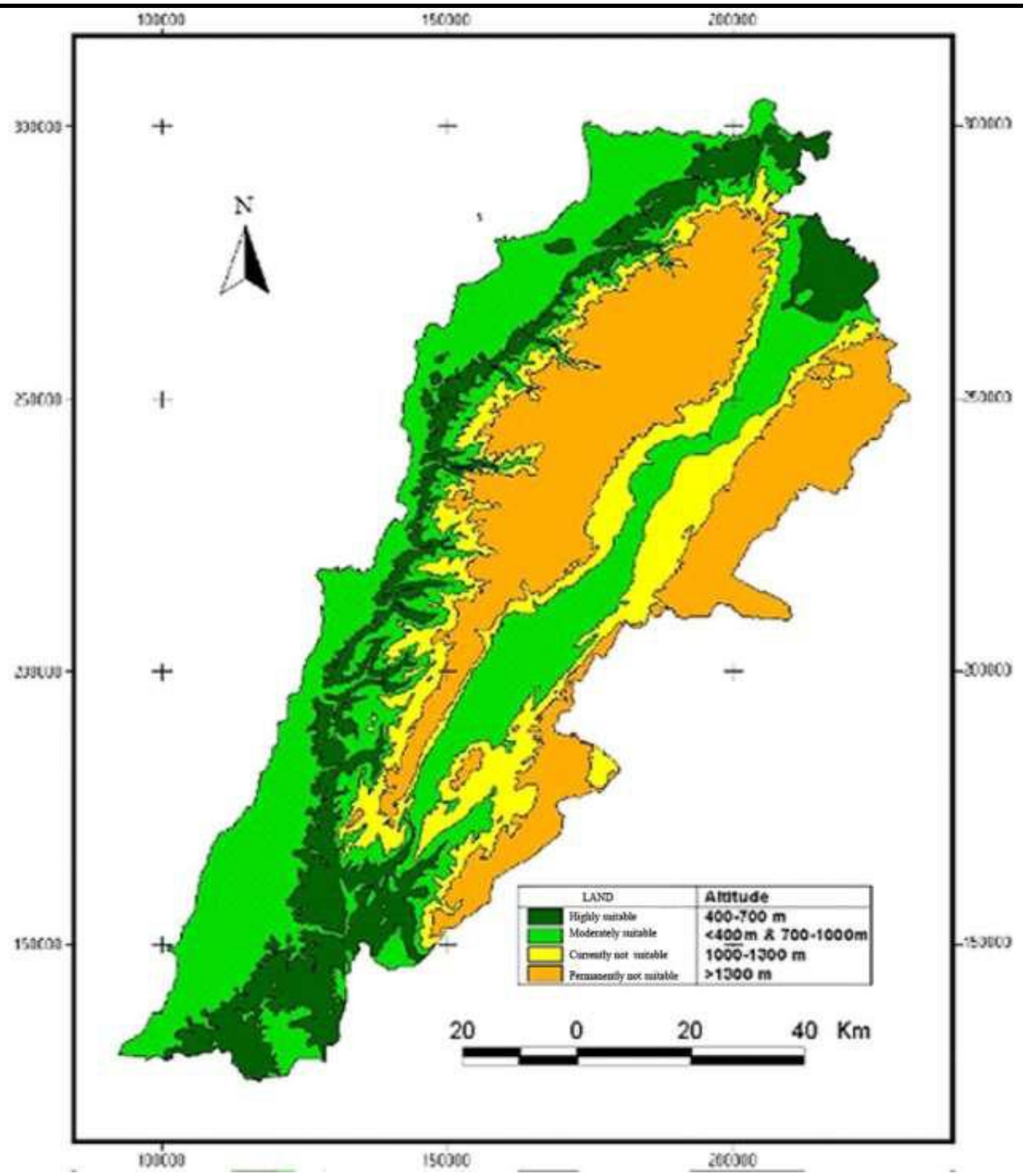

Fig.6: Ability of the Lebanese territory for stone pin reforestation according to altitude. 


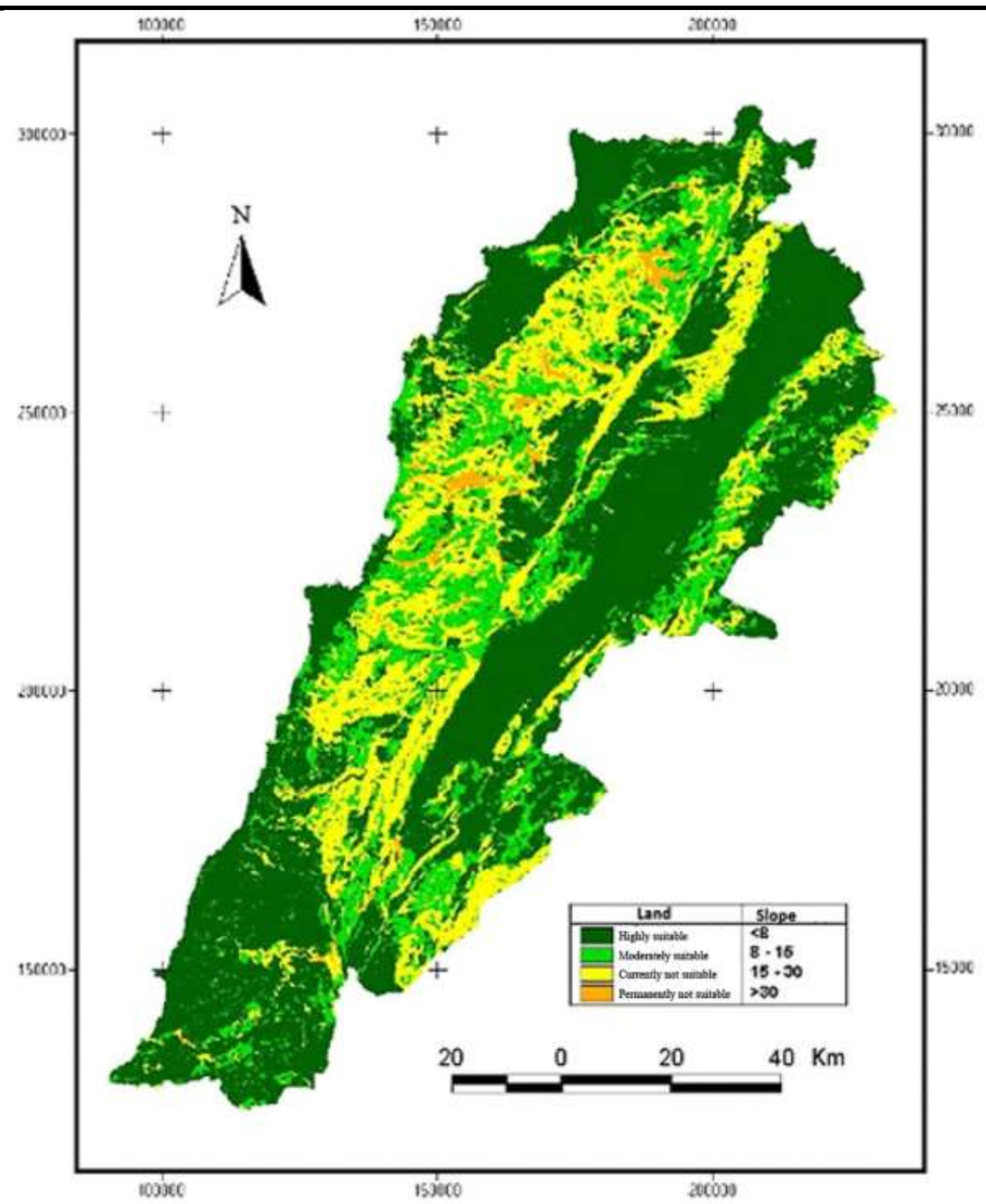

Fig.7: Ability of the Lebanese territory for stone pin reforestation according to slopes. 


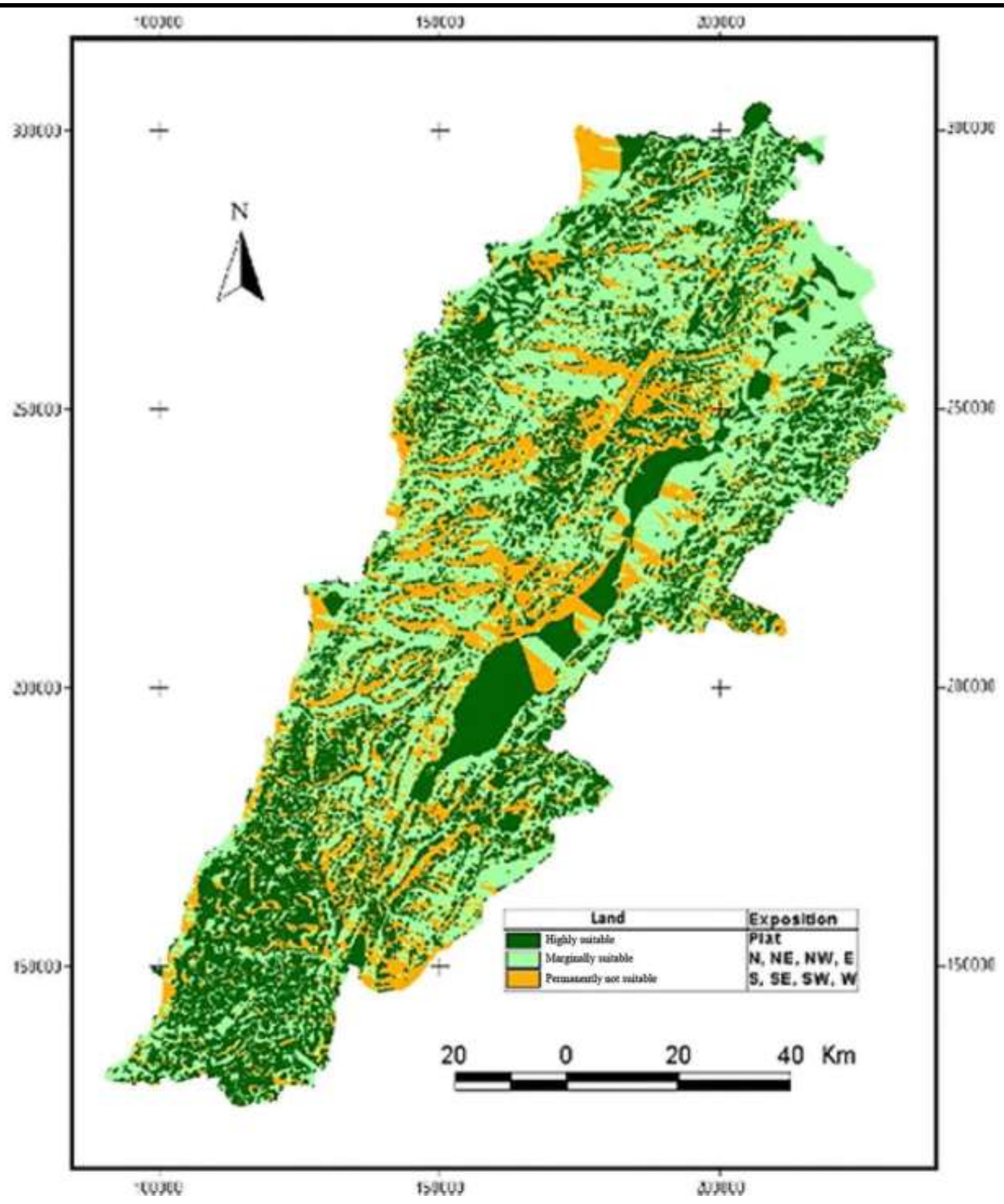

Fig.8: Ability of the Lebanese territory for stone pin reforestation according to exposition. 


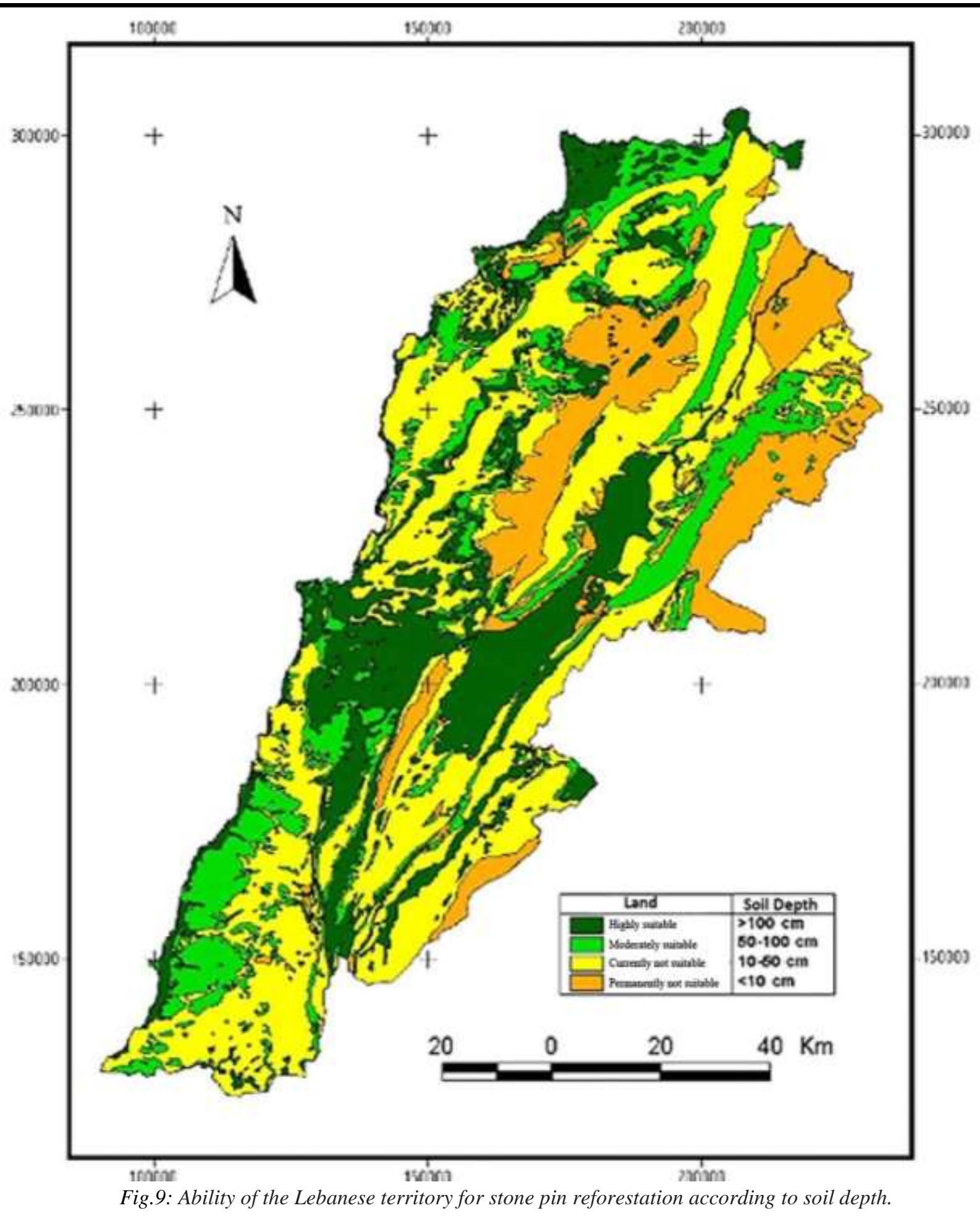




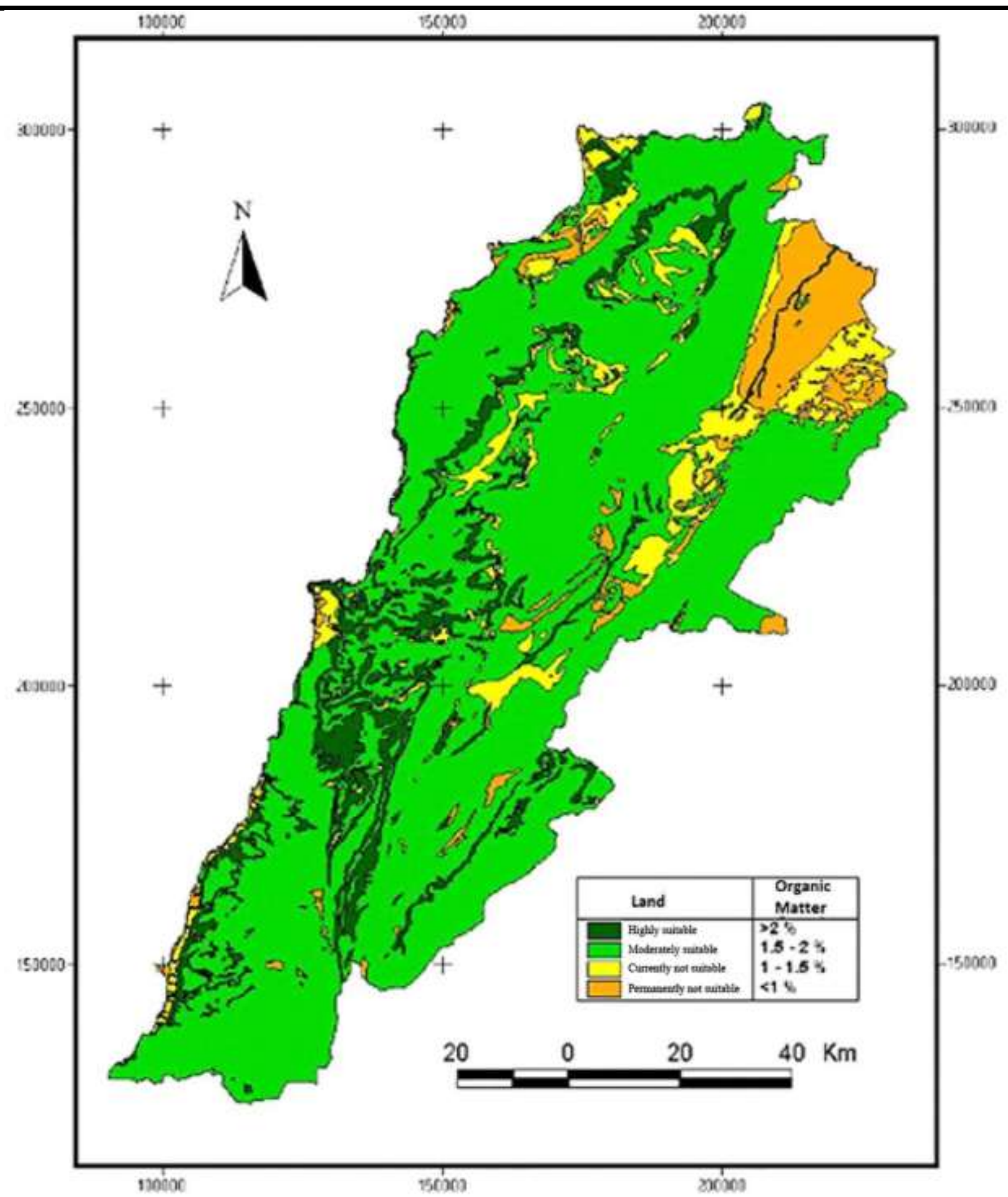

Fig.10: Ability of the Lebanese territory for stone pin reforestation according to soil organic matter. 


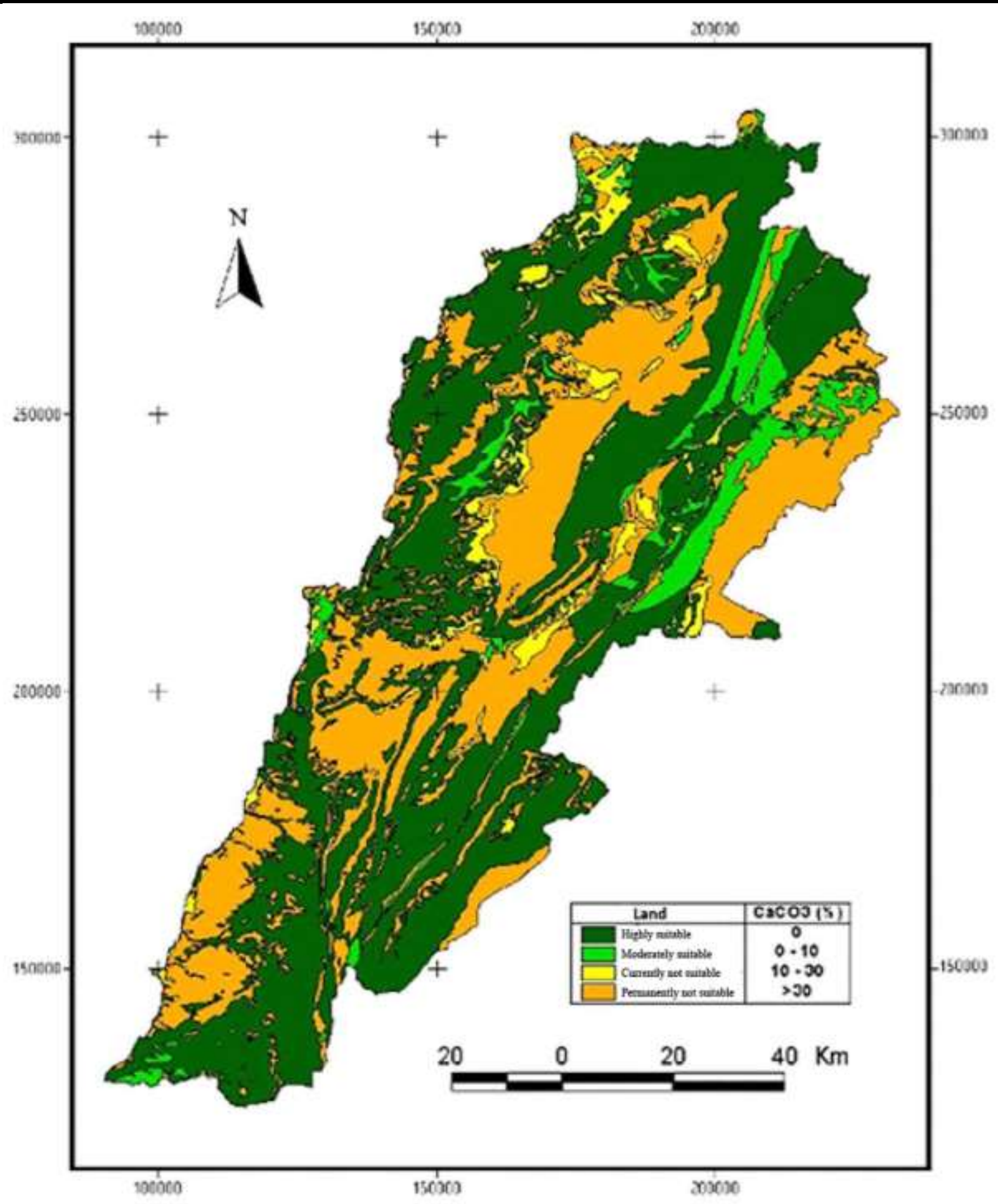

Fig. 11: Ability of the Lebanese territory for stone pin reforestation according to CaCO3 in the soil. 


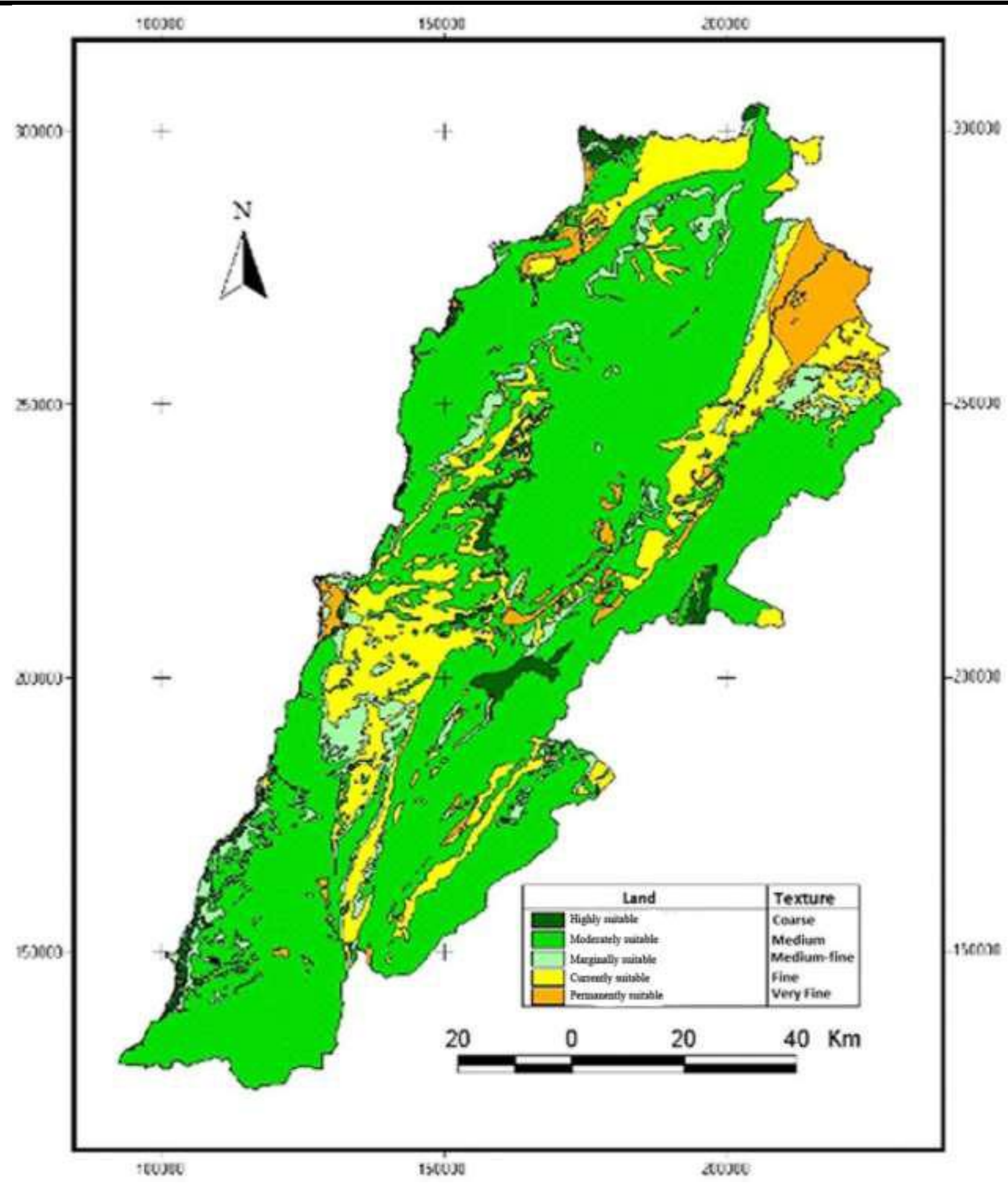

Fig.12: Ability of the Lebanese territory for stone pin reforestation according to soil texture. 


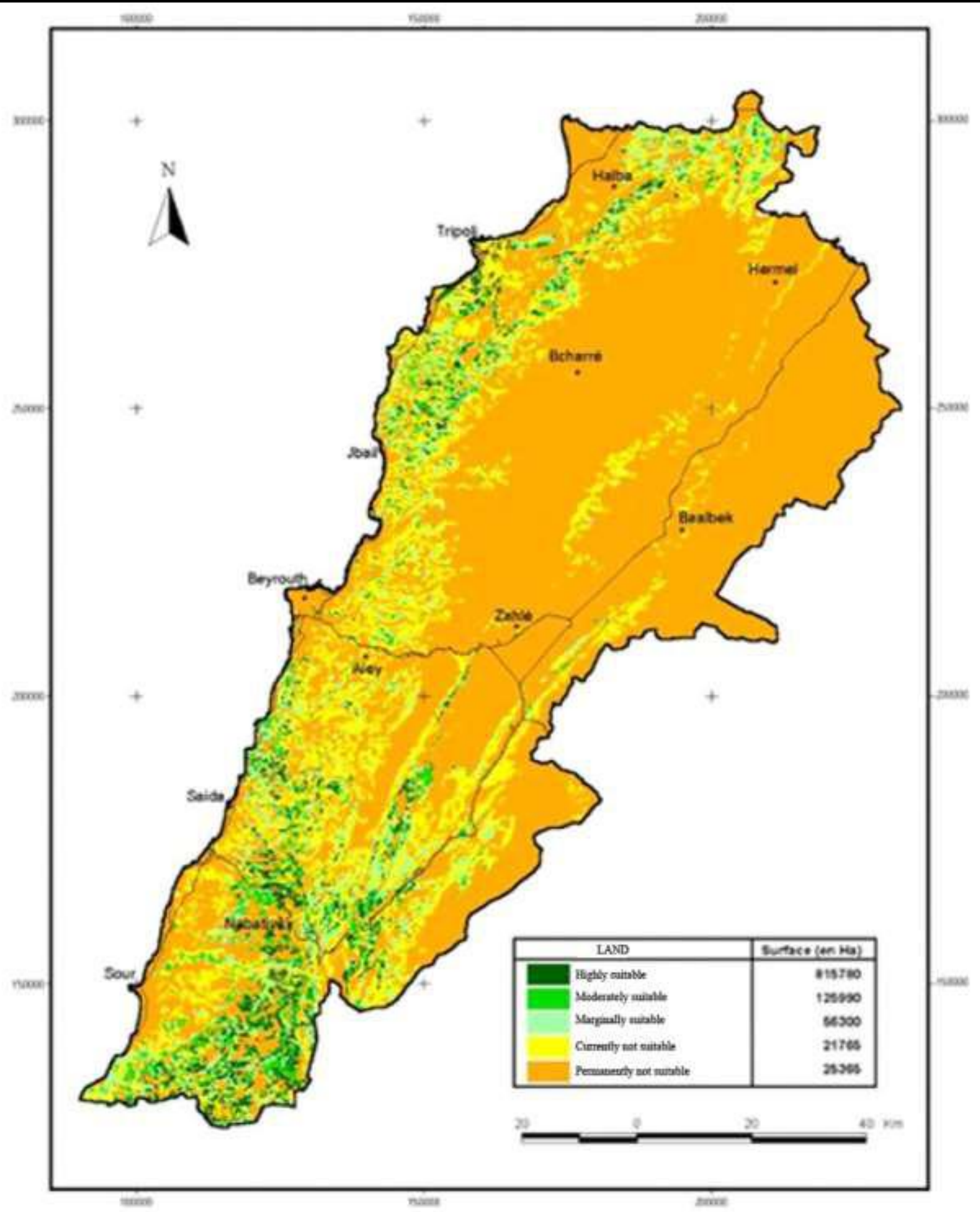

Fig.13: Final map of the ability of the Lebanese territory for stone pine reforestation. 
Table. 1 : Evaluation Table.

\begin{tabular}{|c|c|c|c|c|c|c|c|c|}
\hline \multirow[t]{2}{*}{ Parameters } & \multicolumn{7}{|c|}{ Coefficients $(\mathbf{C i})$} & \multirow{2}{*}{$\begin{array}{c}\text { Poid } \\
\text { S } \\
(\mathbf{P i})\end{array}$} \\
\hline & 1.0 & 0.8 & 0.6 & 0.5 & 0.4 & 0.2 & 0.1 & \\
\hline Altitude (m). & $400-700$ & $\begin{array}{l}<400 \& \\
700- \\
1000\end{array}$ & N/A & $\begin{array}{l}1000- \\
1300\end{array}$ & N/A & N/A & $\begin{array}{l}>13 \\
00\end{array}$ & 3 \\
\hline Slope $\left(^{\circ}\right)$. & $<8$ & $8-15$ & $15-30$ & N/A & $>30$ & N/A & $\begin{array}{l}\mathrm{N} / \\
\mathrm{A}\end{array}$ & 4 \\
\hline Exposition. & Plat. & $\begin{array}{l}\text { N, N-E. } \\
\text { N, N-W. }\end{array}$ & $\begin{array}{l}\text { S, S-E. } \\
\text { S, S-W. }\end{array}$ & N/A & N/A & N/A & $\begin{array}{l}\mathrm{N} / \\
\mathrm{A}\end{array}$ & 4 \\
\hline Soil Depth $(\mathrm{cm})$. & $>100$ & $50-100$ & $10-50$ & N/A & N/A & $<10$ & $\begin{array}{l}\mathrm{N} / \\
\mathrm{A}\end{array}$ & 3 \\
\hline $\begin{array}{l}\text { Soil Organic } \\
\text { Matter }(\%)\end{array}$ & $>2.0$ & $1.5-2.0$ & $1.0-1.5$ & $<1.0$ & N/A & N/A & $\begin{array}{l}\mathrm{N} / \\
\mathrm{A}\end{array}$ & 4 \\
\hline Soil $\mathrm{CaCO}_{3}(\%)$. & 0 & $0-10$ & $10-30$ & N/A & $>30$ & N/A & $\begin{array}{l}\mathrm{N} / \\
\mathrm{A}\end{array}$ & 2 \\
\hline Soil Texture & Coarse & Medium & $\begin{array}{l}\text { medium- } \\
\text { fine }\end{array}$ & N/A & Fine & Very fine & $\begin{array}{l}\mathrm{N} / \\
\mathrm{A}\end{array}$ & 2 \\
\hline $\begin{array}{l}\text { Precipitation } \\
\text { (mm/year). }\end{array}$ & $>900$ & $700-900$ & $500-700$ & N/A & $\begin{array}{l}300- \\
500\end{array}$ & $<300$ & $\begin{array}{l}\mathrm{N} / \\
\mathrm{A}\end{array}$ & 4 \\
\hline $\begin{array}{l}\text { Extreme minimal } \\
\text { Temperature } \\
\left({ }^{\circ} \mathrm{C}\right) .\end{array}$ & $\begin{array}{l}10-15 \& \\
0-55\end{array}$ & -10 & $0-(-5)$ & N/A & N/A & $<(-5)$ & $\begin{array}{l}\mathrm{N} / \\
\mathrm{A}\end{array}$ & 3 \\
\hline Soil Occupation & $\begin{array}{l}\text { Bare and } \\
\text { rocky } \\
\text { soil }\end{array}$ & $\begin{array}{l}\text { Shrub } \\
\text { and } \\
\text { herbaceo } \\
\text { us zones }\end{array}$ & $\begin{array}{l}\text { Sparse } \\
\text { Forests }\end{array}$ & N/A & $\begin{array}{l}\text { Dense } \\
\text { Forests }\end{array}$ & $\begin{array}{l}\text { Agricultur } \\
\text { e, rural } \\
\text { and/or } \\
\text { water } \\
\text { surface }\end{array}$ & $\begin{array}{l}\text { N/ } \\
\text { A }\end{array}$ & 3 \\
\hline
\end{tabular}

